UCRL-ID-126978 Rev 2

\title{
National Ignition Facility Sub-System Design Requirements Automatic Alignment System SSDR 1.5.5
}

\author{
P. VanArsdall \\ E. Bliss
}

September 5, 1996

This is an informal report intended primarily for internal or limited external distribution. The opinions and conclusions stated are those of the author and may or may not be those of the Laboratory.

Work performed under the auspices of the U.S. Department of Energy by the Lawrence Livermore National Laboratory under Contract W-7405-Eng-48. 


\section{DISCLAIMER}

This document was prepared as an account of work sponsored by an agency of the United States Government. Neither the United States Government nor the University of California nor any of their employees, makes any warranty, express or implied, or assumes any legal liability or responsibility for the accuracy, completeness, or usefulness of any information, apparatus, product, or process disclosed, or represents that its use would not infringe privately owned rights. Reference herein to any specific commercial product, process, or service by trade name, trademark, manufacturer, or otherwise, does not necessarily constitute or imply its endorsement, recommendation, or favoring by the United States Government or the University of California. The views and opinions of authors expressed herein do not necessarily state or reflect those of the United States Government or the University of California, and shall not be used for advertising or product endorsement purposes.

This report has been reproduced directly from the best available copy.

Available to DOE and DOE contractors from the Office of Scientific and Technical Information

P.O. Box 62, Oak Ridge, TN 37831

Prices available from (615) 576-8401, FTS 626-8401

Available to the public from the

National Technical Information Service

U.S. Department of Commerce

5285 Port Royal Rd.,

Springfield, VA 22161 


\section{National Ignition Facility}

\section{Sub-System Design Requirements}

\section{Automatic Alignment System SSDR 1.5.5}

\section{Revision 2}

5 September 96

Prepared by:

P. VanArsdall, Integrated Computer Controls Lead Engineer

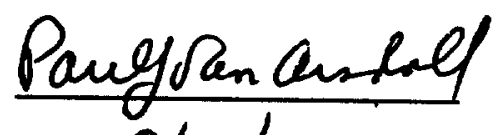

E. Bliss, System Controls System Engineer

Date

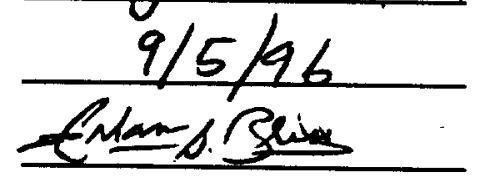

Date $14 / 5 / 96$

Special Equipment Engineering Approval:

R. Sawicki, NIF Associate Project Engineer

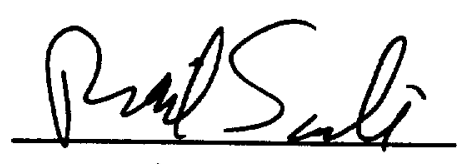

Date

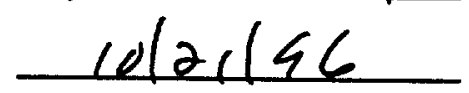

Engineering Review Board Approval:

S. Kumpan, NIF Project Engineer Approval Date

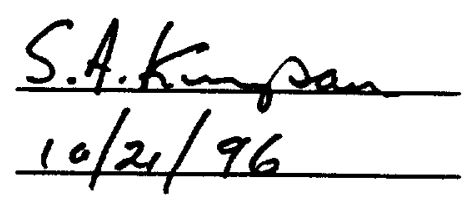




\section{Table of Contents}

Paragraph
1.0
2.0
2.1
2.2
2.3
2.4
2.5
2.6
3.0
3.1 .1
3.1 .3
3.1 .3 .1
3.1 .3 .2
3.1 .3 .3
3.1 .4
3.1 .5
3.2 .00
3.2 .01
3.2 .02
3.2 .03
3.2 .04
3.2 .05
3.2 .06
3.2 .07
3.2 .08
3.2 .09
3.2 .10
3.2 .10 .1
3.2 .10 .2
3.2 .10 .3
3.2 .10 .4
3.2 .10 .5
3.2 .11
3.2 .11 .1
3.2 .11 .2
3.2 .11 .3
3.2 .11 .4
3.2 .12
3.2 .13
3.2 .14
3.4
3.4 .1
3.4 .2
6.0

Title

Scope

Applicable Documents

Applicable NIF Project Documents

Applicable US Government Orders and Standards

Applicable National Consensus Codes and Standards

Applicable LLNL Standards

Supporting Documentation Standards

References

Requirements and Verification

System Description

System Diagrams

Image Processing Algorithms used for Automatic Alignment

Auto Alignment Loop Diagram

Auto Alignment Loop Sequences

System Interfaces

Automatic Alignment System - WBS 1.5.5

Functional Requirements

QA Level Requirements

Full System Alignment Time

Closed Loop Descriptions

Full System Verification Time

Average Loop Process Time

Digitized Image Resolution

Video Used By Automatic Alignment

Pulse Sync

FEP Software Requirement Specification

Lifetime, Replaceability and RAM

Lifetime,

Replaceability

Reliability

Availability

Maintainability

Environmenta/EMI Requirements

Environmental, Temperature and Humidity

Environmental, Plenum Approved/CL2 Cabling

EMI Requirements

Ionizing Radiation

Segmented and Concurrent Operation

Human Factors

Documentation and Records

Logistics

Maintenance

Spares

Revision Record 


\subsection{Scope}

This System Design Requirement document establishes the performance, design, development, and test requirements for the Automatic Alignment System, WBS 1.5.5 which is part of the NIF Integrated Computer Control System (ICCS). This document responds directly to the requirements detailed in ICCS (WBS 1.5) which is the document directly above.

\subsection{Applicable Documents}

This section lists DOE orders, codes, and standards which are applicable to the NIF Integrated Computer Control System. The applicable portions of these documents apply. Applicable LLNL standards are being considered contingent upon the decision of final site selection.

\subsection{Applicable NIF Project Documents}

National Ignition Facility Functional Requirements and Primary Criteria, Revision 1.4, Mar 96.

\subsection{Applicable US Government Orders and Standards}

US. Government DOE General Orders:

DOE 5700.6C-Quality Assurance (flowdown from FRPC and SDR4)

US. Government DOE Orders relating to Safeguards and Security:

DOE Order 1360.2B, Unclassified Computer Security Program (nfd, Contract 48 required)

DOE Order 5300.4D, Telecommunications: Protected Distribution Systems (fd)

DOE Order 5639.6, Classified Computer Security Program (nfd, Contract 48 required)

\subsection{Applicable National Consensus Codes and Standards}

General Standards:

Do not apply to this section.

Safety Standards:

Do not apply to this section.

Software and Electronic Standards:

Ethernet

FDDI

RS-232C

RS-485

IEEE-488

VMEbus

RS-170

Ada 83

Ada 95

$\mathrm{X} 11$

OSF/Motif Motif

Postscript

POSIX

TCP/TP

OSI/ISO

OSF/DCE

OSF/DME
IEEE-802.3 Local Area Network for Data Communications

Fiber Distributed Data Interface, ANSI Standard X3.139-1987

EIA Serial interface standard

EIA Multi-drop serial interface standard

Standard Digital Interface for Programmable Instrumentation, ANSI/IEEE Std 488.1-1987 and ANSI/IEEE Std 488.2-1987

\section{IEEE-1014}

EIA Video interface standard

ANSIMIIL-STD-1815A-1983, programming language

International Standard ANSI/SO/IEC-8652:1995, January 1995

$\mathrm{X}$ Window System, Version 11, windows graphics standard, MIT X Consortium graphical user interface, Open Systems Foundation

Text and graphics printing language, Adobe Systems Inc.

IEEE-1003 portable application programming environment

Protocol stack for network communications

Open Systems Interconnect protocol stack for network communications

Distributed Computing Environment, Open Systems Foundation

Distributed Management Environment, Open Systems Foundation

\subsection{Applicable LLNL Standards}

Do not apply to this section. 


\subsection{Supporting Documentation Standards}

Instrument Society of America, ISA-S5.1, Instrumentation Symbols and Identification

Instrument Society of America, ISA-S5.2, Binary Logic Diagrams for Process Operations

Instrument Society of America, ISA-S5.3, Graphics Symbols for Distributed Control/Shared Display Instrumentation, Logic and Computer Systems

Instrument Society of America, ISA-S5.4, Instrument Loop Diagrams

Instrument Society of America, ISA-S5.5, Graphics Symbols for Process Displays

ANSI/IEEE Std 730.1-1989, IEEE Standard for Software Quality Assurance Plans

Software Guidelines Standards, Practices, and Conventions (Final DRAFT), Applications Development

Department, Lawrence Livermore National Laboratory, August 10, 1992

ANSI/IEEE Std 830-1984, IEEE Guide for Software Requirements Specification

ANSI/IEEE Std 1016-1987, IEEE Recommended Practice for Software Design Descriptions

ANSI/IEEE Std 828-1983, IEEE Standard for Software Configuration Management Plans

ANSI/IEEE Std 982.1-1988, IEEE Standard Dictionary for Measures to Produce Reliable Software

ANSI/IEEE Std 982.2-1988, IEEE Guide for the Use of IEEE Standard Dictionary of Measures to Produce

Reliable Software

The Software Productivity Consortium, Ada Quality and Style Guidelines for Professional Programmers ANSI/IEEE Std 1063-1987, IEEE Standard for Software User Documentation

\subsection{References}

NIF-LLNL-95-044/L-15958-2, National Ignition Facility Quality Assurance Program Plan, September 1995

NIF-LLNL-94-017/L-15958-5, NIF Ancillary Software Quality Assurance Plan, January 12, 1994

NIF-LLNL-93058, National Ignition Facility Functional Requirements and Primary Criteria

\subsection{Requirements and Verification}

\subsubsection{System Description}

The automatic alignment system, using computer hardware and software, centers laser beams on component input apertures and then points the beams through to the next component. Beam focusing is also performed. Digital image processing methods, such as the weighted centroid, are employed to analyze the same sensor images as those observed by operators on TV monitors or windows on an operator console. Automatic alignment is composed of many sequential iterative loops, each of which is responsible for controlling one active component such as a mirror. Many loops in different beams are operated in parallel using specialized FEP units.

Sensors for the Automatic Alignment System are contained in Laser Control WBS 1.7. 


\subsubsection{System Diagrams}

3.1.3.1 Image Processing Algorithms used for Automatic Alignment

\begin{tabular}{|l|l|l|}
\hline Sensor Image Type & Image Features & Processing Algorithm \\
\hline Spot or disk & $\begin{array}{l}\mathrm{X}, \mathrm{Y} \text { position, area, } \\
\text { radius and out-of- } \\
\text { bounds point count }\end{array}$ & $\begin{array}{l}\text { Centroid (thresholded or } \\
\text { weighted) a very fast } \\
\text { calculation }\end{array}$ \\
\hline $\begin{array}{l}\text { Multiple beams (i.e., spot } \\
\text { images) }\end{array}$ & $\begin{array}{l}\text { Array of centroid } \\
\text { values }\end{array}$ & $\begin{array}{l}\text { Blob analysis - tracks many } \\
\text { simple objects at once }\end{array}$ \\
\hline Templates(e.g., crosshairs) & $\begin{array}{l}\mathrm{X}, \mathrm{Y} \text { position, match } \\
\text { goodness value }\end{array}$ & $\begin{array}{l}\text { Correlation matched filter - } \\
\text { robust method }\end{array}$ \\
\hline Gaussian beam profile & $\begin{array}{l}\mathrm{X}, \mathrm{Y} \text { position, fitting } \\
\text { error }\end{array}$ & $\begin{array}{l}\text { Surface fitting - } \\
\text { Gram/Schmidt procedure }\end{array}$ \\
\hline Focusing & $\begin{array}{l}\text { Area (centroid values } \\
\text { checked) }\end{array}$ & $\begin{array}{l}\text { Scanning centroid } \\
\text { minimizing area - slow due } \\
\text { to moving components }\end{array}$ \\
\hline
\end{tabular}




\subsubsection{Auto Alignment Loop Diagram}

Each automatic alignment loop is comprised of many synchronous and asynchronous functions.

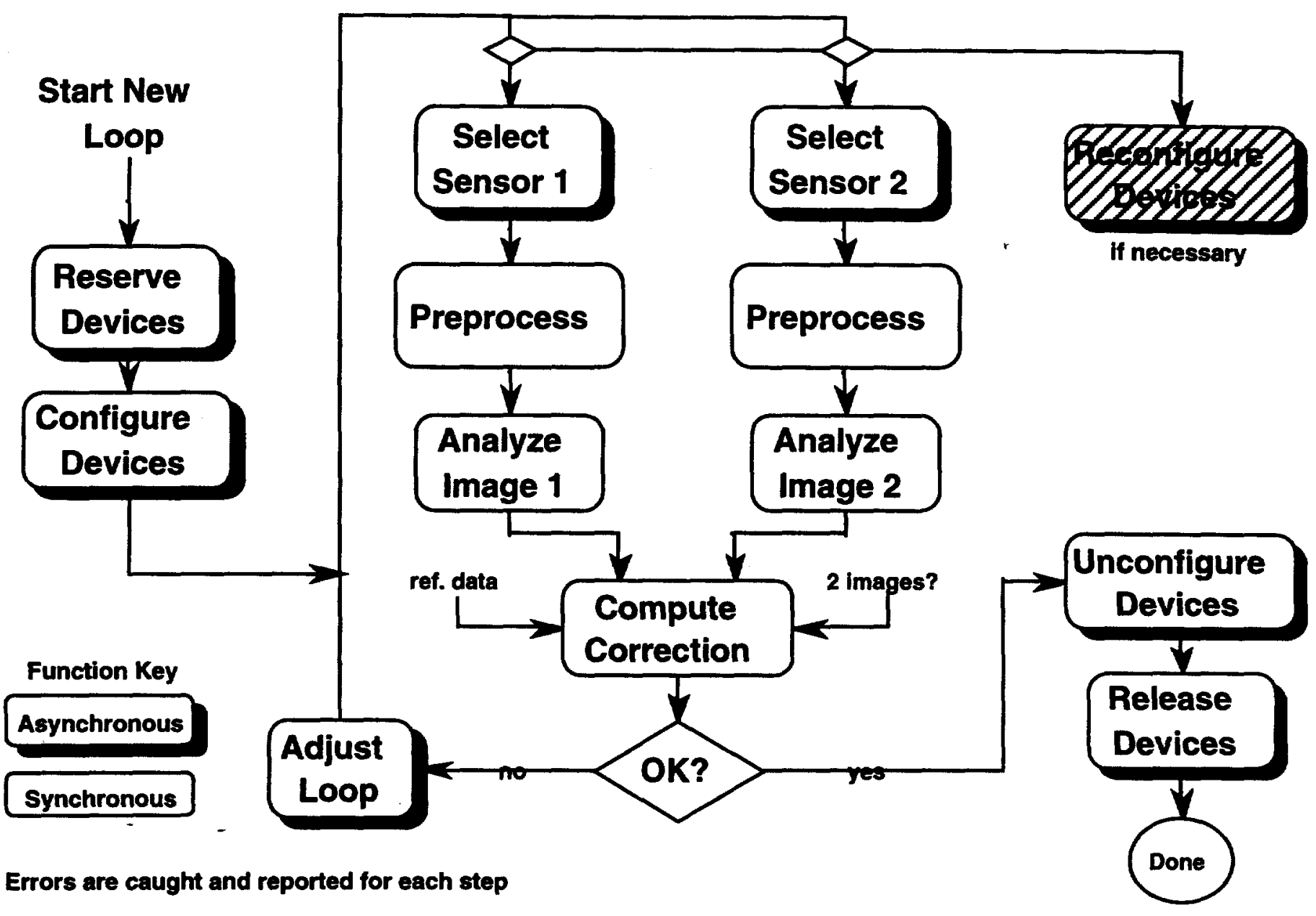




\subsubsection{Auto Alignment Loop Sequences}

This diagram is conceptual and details will be designed during Title 2.

\section{Input \& output sensor loops}
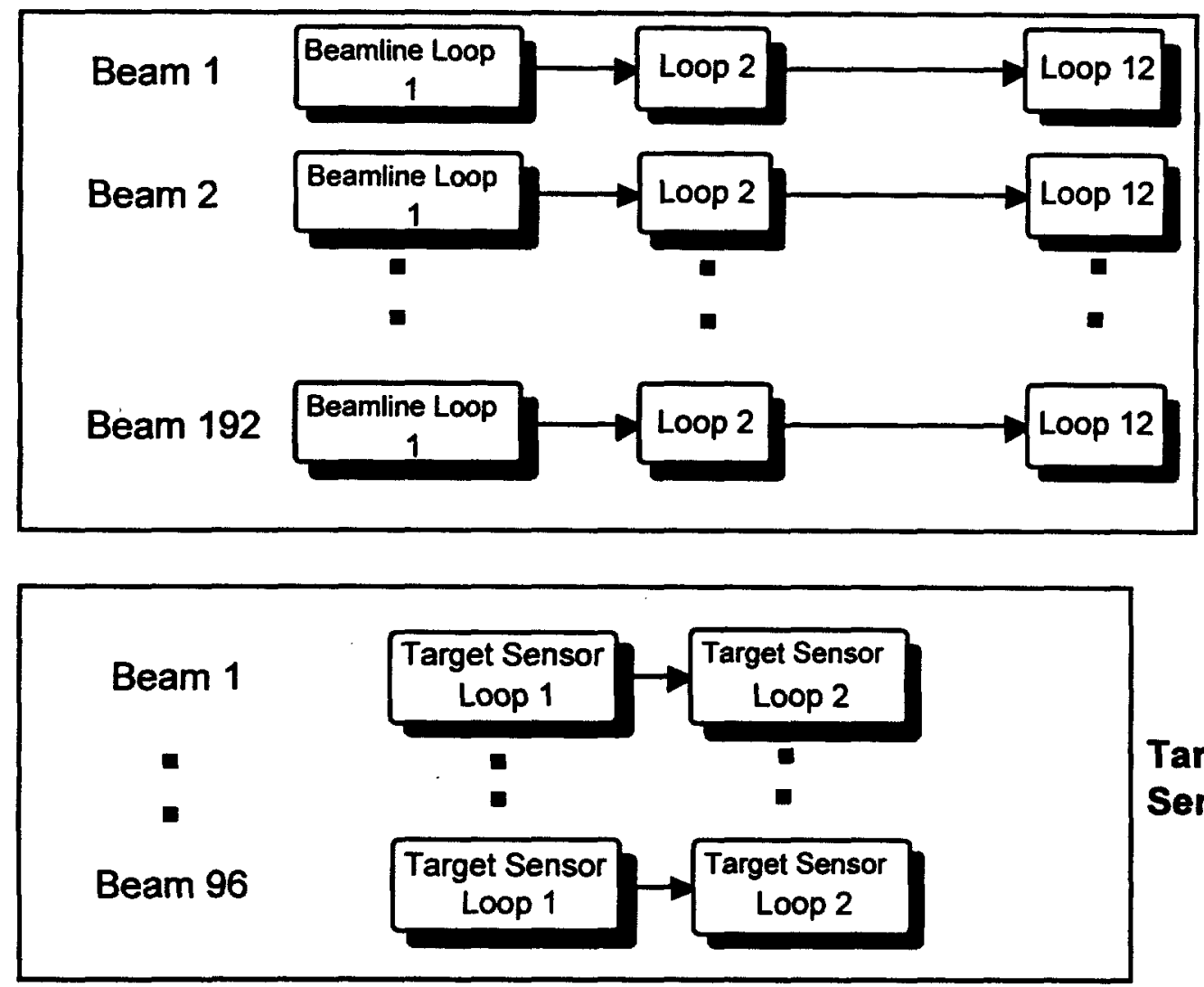

Target Area

Sensor 1

Target Area Sensor Loops

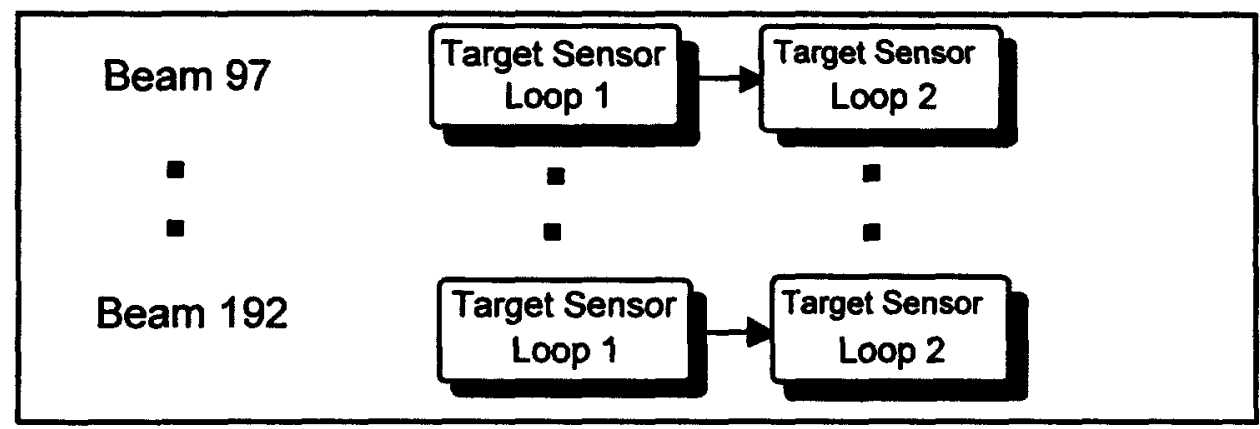

Target Area

Sensor 2

\subsubsection{System Interfaces}

The Automatic Alignment has interfaces to the following WBS systems:

$\begin{array}{ll}\text { WBS 1.5.1.2 } & \text { Computer System (network) } \\ \text { WBS 1.5.2 } & \text { Supervisory Software } \\ \text { WBS 1.5.3 } & \text { Integrated Timing System } \\ \text { WBS 1.5.4 } & \text { Safety Systems (permissives) } \\ \text { WBS 1.5.6.1 } & \text { Video Distribution } \\ \text { WBS 1.7.1 } & \text { Alignment Systems }\end{array}$




\subsubsection{Automatic Alignment System - WBS 1.5.5}

Consists of WBSs:

1.5.5.1 Automatic Alignment Front-end Processors

1.5.5.2 Front-end Processor Software

\subsubsection{Functional Requirements}

The Automatic Alignment System shall:

- point and center laser transport system from fiber-optic front-end to output sensor

- adjust KDP angle to match beam pointing

- point harmonic alignment beams to target chamber sensor

- focus beams on target chamber sensor

- digitize video and provide image processing capability to determine beam references

- perform remote sequencing of motorized alignment components

- maintain historical log of alignment data

- provide non-volatile (disk) storage of parameters and image templates

- provide software development environment for specialized computer equipment

- be modular allowing support of partial system operation during startup or maintenance

- provide a classified processing system for automatic alignment using potentially classified images obtained from the Target Alignment Sensors and the Chamber Center Reference Sensor.

\subsubsection{QA Level Requirements}

The Automatic Alignment System shall adhere to Quality Level 3 specifications.

Reference for QA Level is the NIF QA Plan as stated in paragraph 2.6 of this document.

\subsubsection{Full System Alignment Time}

The Automatic Alignment System shall support an eight (8) hour shot interval. The design of the Automatic Alignment System shall not preclude later support of a four (4) hour shot interval. A supporting analysis document shall be supplied.

Total time for a full laser system automatic alignment, including operator interactions (if required) shall not exceed 1 hour.

\subsubsection{Closed Loop Descriptions}

Approximately 15 loops shall be defined on a per-beam basis. (when data is available)

\subsubsection{Full System Verification Time}

The Automatic Alignment System shall complete a system verification in 30 minutes or less. Verification implies only part of the loops are checked, and that few loops need adjustment.

\subsubsection{Average Loop Process Time}

Average time to close a single loop shall not exceed 15 seconds. A typical loop is assumed to be comprised of analyzing one reference image and three beam images (i.e. 3 iterations).

\subsubsection{Digitized Image Resolution}

Image Processing in the Automatic Alignment System shall operate on a 480 lines by 512 pixel image. Image processing shall make use of gray-scale image data to achieve sub-pixel accuracy where needed. This requirement supports alignment performance and analysis specified in WBS 1.7.1.

\subsubsection{Video Used By Automatic Alignment}

The Automatic Alignment System shall use the same video images that are used by operators. This allows unambiguous verification by operators. 


\subsubsection{Pulse Sync}

The Automatic Alignment System shall utilize a timing pulse which is supplied by Integrated Timing System WBS 1.5.3 to properly time the frame-grabs and video processing to the pulsed laser source.

\subsubsection{FEP Software Requirement Specification}

The detailed requirements of the Automatic Alignment System FEP shall be documented in a separate Software Requirements Specification. The SRS shall include functional requirements for FEP-resident user interfaces, data processing, alarm processing, data logging, trending, device drivers, embedded controller interfacing, or other special hardware requirements.

The SRS shall also include performance or other dynamic requirements as well as other architectural requirements that may imply system partitioning. The FEP SRS shall describe functional requirements that are expected to be implemented by either the supervisory software or other collaborating FEPs.

All FEPs shall conform as much as possible to a common design for the implementation of functional requirements that are shared by more than one instance of an FEP.

\subsubsection{Lifetime, Replaceability and RAM}

\subsubsection{Lifetime,}

Lifetime: The Automatic Alignment System shall operate for 30 years.

\subsubsection{Replaceability}

Any portion of the Automatic Alignment System which cannot reasonably be designed for 30 year lifetime shall be designed to be replaced or repaired at reasonable cost in a timely manner consistent with the overall availability of the System.

\subsubsection{Reliability}

The Automatic Alignment System shall have an overall reliability of $99.94 \%$. Reliability is defined as the probability of meeting the minimum requirements of the experiment per no-yield shot.

\subsubsection{Availability}

The Automatic Alignment System shall have a shot availability of at least $99.06 \%$. The Automatic Alignment System is unavailable when it is undergoing unplanned maintenance. Unplanned maintenance includes failure detection and active repair as well as logistic and administrative downtimes.

\subsubsection{Maintainability}

The Automatic Alignment System shall have a scheduled maintenance plan that fits within an overall annual plant goal of 69 days. The unplanned maintenance goal is 2.5 days per year. Opportunistic maintenance activities are performed between shots. and during other system downtimes.

\subsubsection{Environmental/EMI Requirements}

\subsubsection{Environmental, Temperature and Humidity}

The Automatic Alignment System shall be capable of operating in the temperature and humidity previously specified for the laser and target area building. In general, the Automatic Alignment System components are capable of operating in a standard commercial temperature and humidity of $5 \mathrm{C}$ to $40 \mathrm{C}$ (41 to $104 \mathrm{~F}$ ) and $20 \%$ to 80 $\%$ RH non-condensing when installed in their appropriate enclosures.

\subsubsection{Environmental, Plenum Approved/CL2 Cabling}

All Automatic Alignment System cabling installed in air plenums shall use plenum approved cabling. Otherwise controls cabling shall conform to CL2 specifications. 


\subsubsection{EMI Requirements}

All Automatic Alignment System electronic equipment shall be designed or purchased to tolerate, where warranted, an operating environment of $50 \mathrm{~V} / \mathrm{m}$ external electrical field and $0.1 \mathrm{~A} / \mathrm{m}$ external magnetic field without adverse effects. (ref ANSI C95.1-1991)

\subsubsection{Ionizing Radiation}

Ionizing Radiation effects are an issue only inside the target room. Inside the target room careful consideration shall be given to the radiation and EMI effects as described in "Radiation and EMI Effects in the NIF

Environment", UCRL-ID-118202.

\subsubsection{Segmented and Concurrent Operation}

The Automatic Alignment System shall be capable of operating the NIF in a segmented mode with the segments functioning concurrently in different configurations. As an example, a portion of the laser may be under maintenance or construction and the rest of the laser operational. The Automatic Alignment System shall support the area under construction with appropriate test sequences, diagnostics and construction debugging tools, while simultaneously supporting shot sequences on the operational segment of the laser.

\subsubsection{Human Factors}

The Automatic Alignment System shall be designed in an ergonometric fashion to ensure that reliability during operation and maintenance is sustained at a level consistent with meeting overall availability and reliability objectives. Consistency in displays, warnings, and human interfaces should be maintained throughout the Laser System and, if possible, throughout the NIF facility (i.e. GUI displays, access ports, tooling). The requirement is related to paragraph 3.2 .530 of this document.

\subsubsection{Documentation and Records}

The Automatic Alignment System shall provide sufficient documentation to comply with the NIF Quality Assurance Plan, and DOE Order 5700.6C, Quality Assurance, Criterion-4 Documents and Records, which states: "Documents shall be prepared, reviewed, approved, issued, used and revised to proscribe processes, specify requirements or establish design. Records shall be specified, prepared, reviewed approved and maintained."

Examples of documents that should be controlled include drawings, data files, calculations, specifications, computer codes, purchase orders, vendor supplied documents, procedures, work records and data sheets and test records. Revisions should be reviewed by the organizations that originally prepared and approved the documents. Controlled documents should be distributed to those doing the work.

\subsection{Logistics}

\subsubsection{Maintenance}

As a part of the design/construction project, the Automatic Alignment System shall provide all equipment required to inspect, service, and maintain all subsystems within the Integrated Computer Control System to meet the maintainability and availability requirements. Maintenance equipment shall include all handling fixtures, lifting equipment, and other special tools not otherwise available within the NIF, that are necessary to perform any planned (scheduled or unscheduled) maintenance activity.

\subsubsection{Spares}

As a part of the design/construction project, the Automatic Alignment System shall provide an initial complement of spare parts as required to activate the system. 


\subsection{Revision Record \\ Rev \\ letter Date \\ A . 12Mar96 \\ A 30May96 \\ $2 \quad$ 09Aug96 \\ Change by Description \\ Severyn Convert to FileMaker, update \\ Severyn Post Mid Title-1 update \\ Severyn para 2.6, Update to new QA Reference.}

para 3.2.00, Add classified processing system for autoalignment images

para 3.2.01, Update QA levels to 1996 stds.

para 2.2, was TBD, added ref. to DOE QA document, and refs. to Computer Security DOE Orders because of classified/unclassified operation).

para 2.3, General and Safety sections were TBD, changed to not applicable.

para. 2.4, was TBD, changed to not applicable.

Christensen

Convert to Word

Severyn

Call rev B=rev 2 for Sherpa, shrink diagrams to fit.

Deleted phrase "Automatic Alignment System" from many para. titles to be consistent in titles. Updated Table of Contents to reflect this change. No text change.

para 3.1.3.2 Updated Loop Diagram, "Digitize \& Preprocess" becomes "Preprocess". per PVA.

para 3.1.3.3, Added "This diagram is conceptual and details will be designed during Title 2." per PVA.

para 3.2.06 replaced "...accuracy shall be within \pm 1 pixel in $X$ and \pm 1 pixel in $Y$ ", with "...shall make use of gray-scale image data to achieve sub-pixel accuracy where needed." per Bliss. 


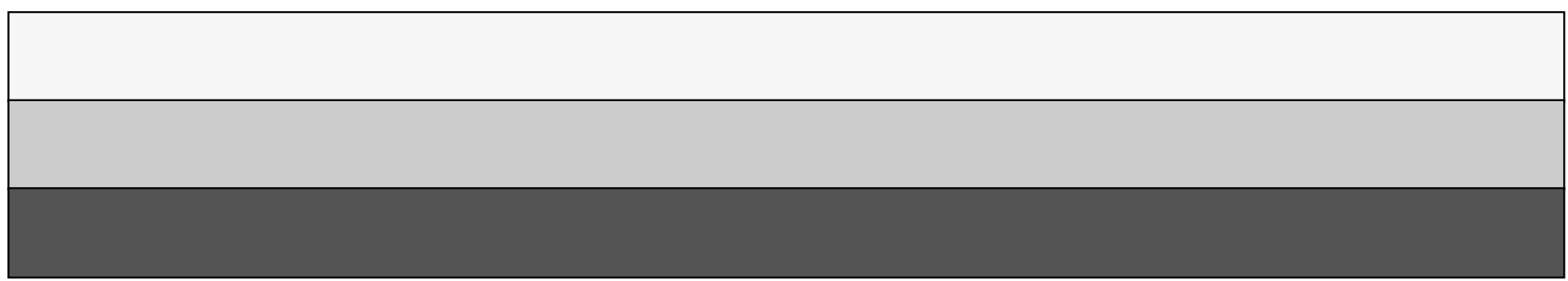

